\title{
RESEARCH
}

Open Access

\section{Influence of China's 2009 healthcare reform on the utilisation of continuum of care for maternal health services: evidence from two cross-sectional household surveys in Shaanxi Province}

Xiaojing Fan ${ }^{1} \mathbb{D}$, Meghan Bruce Kumar ${ }^{2,3}$, Zhongliang Zhou ${ }^{1 *}$, Ching-Hung Lee ${ }^{1}$, Duolao Wang ${ }^{4^{*}}$, Haixia Liu ${ }^{5}$, Shaonong Dang ${ }^{6}$ and Jianmin Gao ${ }^{1}$

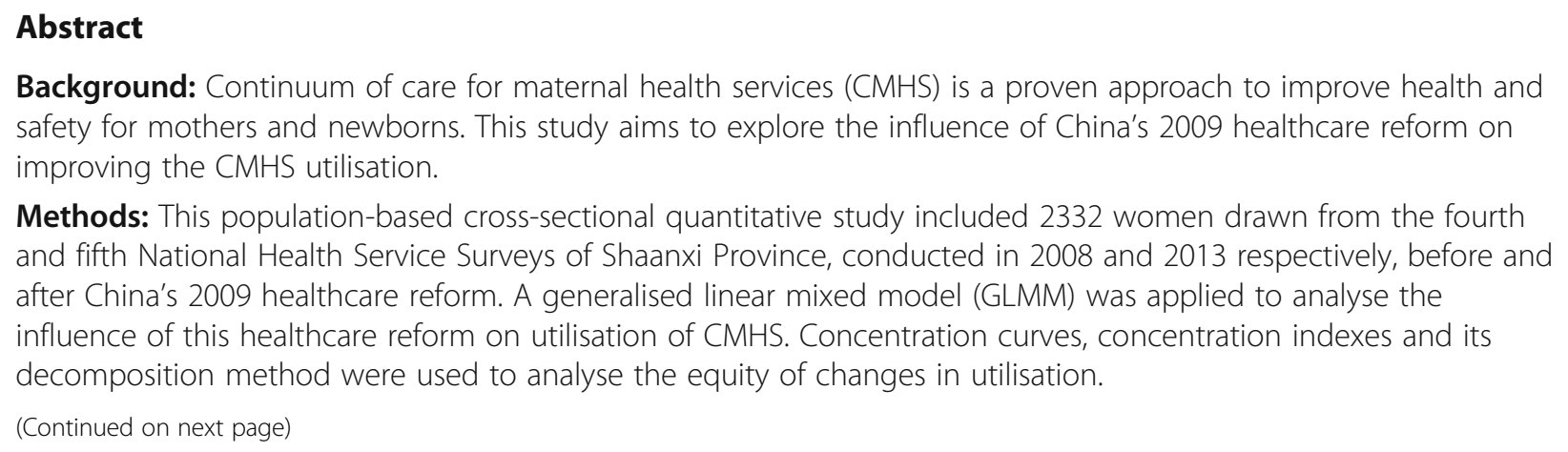

Methods: This population-based cross-sectional quantitative study included 2332 women drawn from the fourth and fifth National Health Service Surveys of Shaanxi Province, conducted in 2008 and 2013 respectively, before and after China's 2009 healthcare reform. A generalised linear mixed model (GLMM) was applied to analyse the influence of this healthcare reform on utilisation of CMHS. Concentration curves, concentration indexes and its decomposition method were used to analyse the equity of changes in utilisation.

*Correspondence: zzliang1981@163.com; duolao.wang@|stmed.ac.uk

${ }^{1}$ School of Public Policy and Administration, Xi'an Jiaotong University, No. 28 Xianning West Road, Xi'an 710049, Shaanxi, China

${ }^{4}$ Department of Clinical Sciences, Liverpool School of Tropical Medicine, Liverpool L3 5QA, UK

Full list of author information is available at the end of the article

(c) The Author(s). 2020 Open Access This article is licensed under a Creative Commons Attribution 4.0 International License, which permits use, sharing, adaptation, distribution and reproduction in any medium or format, as long as you give appropriate credit to the original author(s) and the source, provide a link to the Creative Commons licence, and indicate if changes were made. The images or other third party material in this article are included in the article's Creative Commons licence, unless indicated otherwise in a credit line to the material. If material is not included in the article's Creative Commons licence and your intended use is not permitted by statutory regulation or exceeds the permitted use, you will need to obtain permission directly from the copyright holder. To view a copy of this licence, visit http://creativecommons.org/licenses/by/4.0/ The Creative Commons Public Domain Dedication waiver (http://creativecommons.org/publicdomain/zero/1.0/) applies to the data made available in this article, unless otherwise stated in a credit line to the data. 
(Continued from previous page)

Results: This study showed post-reform CMHS utilisation was higher in both rural and urban women than the CMHS utilisation pre-reform (according to China's policy defining CMHS). The rate of CMHS utilisation increased from 24.66 to $41.55 \%$ for urban women and from 18.31 to $50.49 \%$ for rural women (urban: $X^{2}=20.64, P<0.001$; rural: $\left.X^{2}=131.38, P<0.001\right)$. This finding is consistent when the WHO's definition of CMHS is applied for rural women after reform (12.13\% vs 19.26\%; $\left.X^{2}=10.99, P=0.001\right)$; for urban women, CMHS utilisation increased from 15.70 to $20.56 \%\left(x^{2}=2.57, P=0.109\right)$. The GLMM showed that the rate of CMHS utilisation for urban women postreform was five times higher than pre-reform rates $(O R=5.02,95 \% \mathrm{CL}: 1.90,13.31)$; it was close to 15 times higher for rural women $(\mathrm{OR}=14.70,95 \% \mathrm{CL}: 5.43,39.76)$. The concentration index for urban women decreased from 0.130 pre-reform (95\%Cl: $-0.026,0.411)$ to -0.041 post-reform $(95 \% \mathrm{Cl}$ : - 0.096, 0.007); it decreased from 0.104 (95\%Cl: $0.012,0.222)$ to $0.019(95 \% \mathrm{Cl}$ : $-0.014,0.060)$ for rural women. The horizontal inequity index for both groups of women also decreased (0.136 to -0.047 urban and 0.111 to 0.019 for rural).

Conclusions: China's 2009 healthcare reform has positively influenced utilisation rates and equity of CMHS's utilisation among both urban and rural women in Shaanxi Province. Addressing economic and educational attainment gaps between the rich and the poor may be effective ways to improve the persistent health inequities for rural women.

Keywords: Healthcare reform, Continuum of care for maternal health services, Equity, National Health Service Surveys, China

\section{Introduction}

The maternal mortality ratio (MMR) has rapidly reduced globally during the past decades, declining from 385 to 216 maternal deaths per 100,000 livebirths between 1990 and 2015 [1]. Despite global progress in reducing maternal mortality, MMR in low- and middle-income countries (LMICs) is still seven times higher than in highincome countries [2]. In China, the current MMR of 27 per 100,000 live births is still 2-6 times that of developed countries (e.g. 14 deaths per 100,000 in USA; 9 deaths per 100,000 in United Kingdom; 4 deaths per 100,000 in Italy and Sweden), as described by the World Health Organisation (WHO) [2]. Prenatal care penetration is high, with more than $80 \%$ of pregnant women attending $\geq 4$ antenatal visits and delivering in hospital, yet only $25 \%$ of women receive $\geq 3$ postnatal visits within 42 days after delivery $[3,4]$. One possible means of further reducing the MMR in China would be improving adherence to postnatal visits through continuity of care (COC). COC requires access to care throughout one's lifecycle, including adolescence, pregnancy, childbirth, the postnatal period, and childhood [5]. Scholars have proposed COC as a key framework for tracking maternal and neonatal health and assessing reductions in maternal and neonatal deaths $[5,6]$. COC for maternal health services (CMHS) utilisation is defined by pregnant women attending antenatal visits, delivery in health facilities and receiving postnatal visits from health professionals in their homes continuously from pregnancy to 42 days after delivery [7]. Studies from Lancet and PLOS ONE showed adherence to full CMHS can reduce neonatal mortality by $36-67 \%$ and reduce combined perinatal and maternal mortality by $15 \%[8,9]$. However, CMHS has not been adequately implemented and assessed in low- and middle-income countries (LMICs) [10-12].
China embarked on a comprehensive healthcare reform in 2009 aimed at providing all citizens with equal access to basic health care with reasonable quality and sufficient financial risk protection [13]. The reform established the national primary and critical public health service in order to promote health for all, with a focus on attending prenatal visits, hospital delivery and receiving postnatal visits at the full maternal period [1416]. In China, existing research on the healthcare reform impacts primarily focuses on prenatal visits, hospital delivery or postnatal visits separately. Recent studies have evaluated socio-economic inequalities and found socioeconomic determinants of prenatal and postnatal visits [17-19], explored influence of health policy on improving the utilisation of hospital delivery [20], prenatal or postnatal visits [21], fewer studies explore the utilisation of CMHS. To date, there has been some research exploring the determinants, effects, value and measurement of CMHS in LMICs outside of China: in Lao PDR [22], Nepal [23], Tanzania [10], South Africa [11], Cambodia [24]. This study aimed to fill the study gap on exploring the influence of health policy on improving the utilisation of CMHS in one province of China. We hypothesise that the utilisation of CMHS has improved after the introduction of the comprehensive health care reform.

In this study, two rounds of a representative crosssectional household survey are used to analyse the influence of the 2009 Chinese healthcare reform on the utilisation of CMHS in Shaanxi Province. This study also provides policy recommendations for further improving maternal health care utilisation in China and narrowing the gap in MMR between LMICs and high-income countries. 


\section{Methods}

\section{Study design and sample}

This study analyses the influence of the 2009 Chinese healthcare reform on CMHS utilisation in Shaanxi Province. Shaanxi Province, in the west of China, was selected as the study area because it is the type of region that the reform intended to target: predominantly rural (48.69\% of population) and having a high proportion of low socioeconomic status in the population. By the end of 2013, Shaanxi had a population of roughly 37.60 million with a per capital Gross Regional Product (GRP) of 42,692 Chinese yuan. In the same year, the birth rate was $10.01 \%$ and the natural growth rate was $3.86 \%$ [25].

The National Health Service Survey (NHSS) is a population-based cross-sectional nationally representative survey commissioned by the China's National Health Commission every 5 years [26-28]. Based on the structure of Chinese administrative districts and the imbalanced population distributions among the different provinces, a multi-stage stratified cluster randomized design was used to provide a representative sample in each province. Data presented in this paper were drawn from the fourth (in 2008) and fifth (in 2013) NHSS conducted in Shaanxi province before and after the 2009 Chinese healthcare reform.

In each survey round, face-to-face interviews were collected by the investigators trained by China's National Health Commission using a household health questionnaire that mainly included open-ended questions (see Supplementary Questionnaire S1 and S2 online). Data on maternal socio-economic status (including area, age, education, health insurance, annual personal expenditure, employment) as well as chronic disease, parity, antenatal visits, hospital delivery and postnatal visits from pregnancy to 42 days after delivery were collected in the interview. During data collection, experts provided supervision and revisited 5\% of the sampled households to check the accuracy of data recorded by interviewers. They asked 14 key questions again to check the consistency of the information recorded and the consistency should be at least 95\%. The Myer's Blended Index was used to assess the representativeness of the sample (1.67 in the 4th NHSS and 1.62 in 5th NHSS), indicating that in both surveys there was no significant difference between the sampled age distribution and the overall age distribution of Shaanxi Province [21, 29].

Details of the NHSS sampling and data that are included in this paper are provided in Fig. 1. Specifically, we only included women whose last delivery occurred after January 2010, considering the official inception date of the health system reform (September 2009). This gave us a sample of 638 women in the fourth NHSS and 1694 women in the fifth NHSS in this analysis.

\section{Indicators}

China's 2009 healthcare reform in this study refers to a series of measures introduced and implemented after 2009 to strengthen women's maternal health care, mainly including through the national public health service. According to WHO definition, the utilisation of CMHS is categorized as: women who attended $\geq 4$ prenatal visits, had hospital delivery and received $\geq 3$ postnatal visits from pregnancy to 42 days after delivery [30]. In the level of China, the utilisation of CMHS is categorized as: women who attended $\geq 5$ prenatal visits, had hospital delivery and received $\geq 1$ postnatal visit(s) from pregnancy to 42 days after delivery [31, 32]. We analysed rural and urban population separately and compared them to look at geographic equity, allowing us to account for the difference between rural and urban populations in terms of income, education and health service utilisation [33].

\section{Statistical analysis}

In this study, sample data has been checked for missing data and outliers and cleaned prior to data analysis. Descriptive analysis was performed to show the demographic information of maternal women in the sample and their CMHS status. A generalised linear mixed model (GLMM) including both fixed and random effects was used in this study to show the association between China's 2009 healthcare reform and CMHS utilisation when controlling for other confounding factors. The healthcare reform was specified as fixed effects, women's family code as a random effect; maternal women's age, education, employment, annual personal expenditure, health score, health insurance, chronic disease and parity were included as covariates. The model we used was as following:

$$
\eta\left(y_{i j}\right)=\beta_{0 j}+\beta_{1 j} x_{1 i}+\beta_{2 j} x_{2 i}+\cdots+\beta_{p j} x_{p i}+\varepsilon_{i j}
$$

In Eq. (1), the linear prediction $\eta$ is the combination of the fixed and random effects excluding the residuals. $y_{i j}$ is the rate of CMHS utilisation. $\beta_{0 j}$ is a constant, $\beta_{p j}$ represents the effects of $x_{p i}$ on $y$, and $\varepsilon_{i j}$ is a random error. The link function is binomial.

Concentration curve, concentration index (CI) and horizontal inequity index (HI) were used to measure the equity of CMHS utilisation. Before measuring equity, we first measured inequality. Concentration curve and $\mathrm{CI}$ were used to measure the extent of income-related inequality of CMHS utilisation. This is calculated as twice the area between the concentration curve and the line of equality and changed from -1 to 1 [34]. A positive concentration index means that high-income women utilize more CMHS utilisation than their low-income counterparts and negative one means the low-income group 


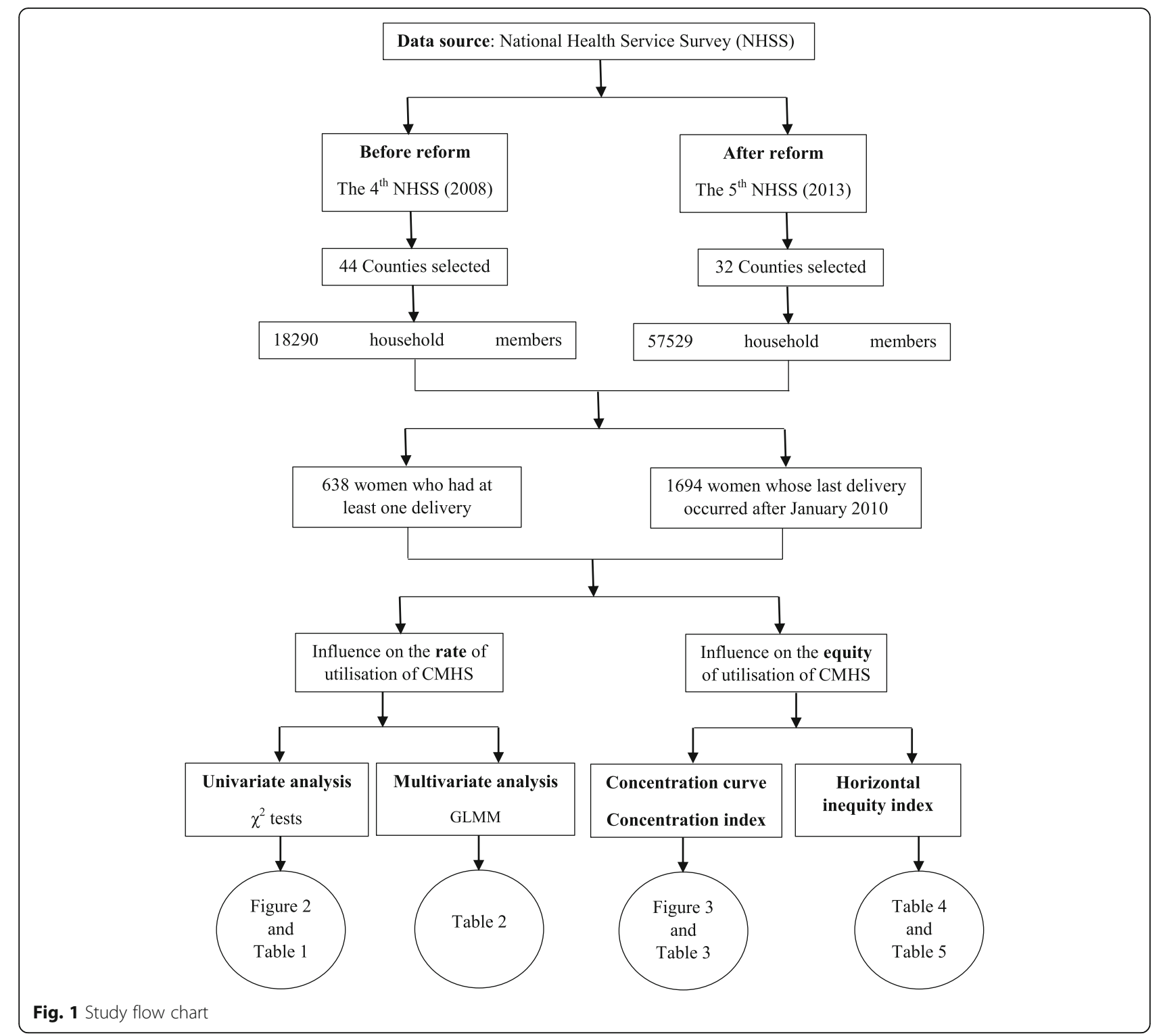

utilizes more CMHS utilisation than their rich counterparts, the formula is as following:

$$
C=\frac{2}{\mu} \operatorname{cov}_{w}\left(y_{i}, R_{i}\right)
$$

where $C$ stands for concentration index, $y_{i}$ is CMHS utilisation index, $\mu$ is the mean of CMHS utilisation index, and $R_{i}$ is the fractional rank of annual personal consumption expenditure distribution.

Inequality can be further explained by decomposing the concentration index into its determining components, then horizontal inequity index (HI) can be computed by subtracting the contribution of need variables (such as women's age, health score and chronic disease) from the concentration index of CMHS utilisation; it is a summary measure of the magnitude of inequity in the dependent variable [35]. These determinants were selected according to previous research but constrained by the variables collected in the investigation [22, 36]. A probit regression model was used to indirectly standardize the CMHS utilisation since the outcome variable is binary. As the standardization of health utilisation holds for a linear model of healthcare, we applied the linear approximation to the probit model to extract marginal effects of each determinant on observed probabilities of the outcome variable. The formula for the concentration index decomposition can be written as follows:

$$
y_{i}=G\left(\alpha+\sum_{j} \beta_{j} x_{j i}+\sum_{k} \gamma_{k} z_{k i}\right)+\varepsilon_{i}
$$


$G$ is functional transformation, $y$ is the dependent variable, $x_{j i}$ are needs variables, and $z_{k i}$ are control variables. Then the standardized need was estimated using the following equation:

$$
\begin{aligned}
\hat{y}_{i}^{I S}= & y_{i}-G\left(\hat{\alpha}+\sum_{j} \hat{\beta}_{j} x_{j i}+\sum_{k} \hat{\gamma}_{k} \bar{z}_{k}\right)+\frac{1}{n} \\
& \times \sum_{i=1}^{n} G\left(\hat{\alpha}+\sum_{j} \hat{\beta}_{j} x_{j i}+\sum_{k} \hat{\gamma}_{k} \bar{z}_{k}\right)
\end{aligned}
$$

where $\hat{y}_{i}^{I S}$ is standardized continuum of maternal health service utilisation, $n$ is sample size. The more CMHS allocated to the population with greater need, the less inequity of CMHS utilisation.
The statistical analyses were performed using STATA statistical software version 12.0 (StataCorp LP, College station 77,845 , USA). A two-tailed $P$ value $<0.05$ was considered statistically significant.

\section{Results}

Increases in rate of utilisation of CMHS post-reform

According to China's definition of CMHS, there were increases in utilisation rate after China's 2009 healthcare reform both for urban and rural women (urban: $X^{2}=20.64, \quad P<0.001 ; \quad$ rural: $\quad X^{2}=131.38, \quad P<0.001$; Table 1) compared with the rate of CMHS utilisation pre-reform. This finding is consistent when the WHO

Table 1 Distribution of continuum of care for maternal health service utilisation among maternal women's socioeconomic

\begin{tabular}{|c|c|c|c|c|c|c|}
\hline \multirow[t]{2}{*}{ Variables } & \multicolumn{3}{|c|}{ Urban $(n=912)$} & \multicolumn{3}{|c|}{ Rural $(n=1420)$} \\
\hline & No & Yes & $P$ & No & Yes & $P$ \\
\hline \multicolumn{3}{|l|}{ Healthcare reform } & $<0.001$ & & & $<0.001$ \\
\hline Before & 167(29.61) & $55(15.80)$ & & $336(40.88)$ & 80(13.38) & \\
\hline After & 397(70.39) & 293(84.20) & & $486(59.12)$ & $518(86.62)$ & \\
\hline \multicolumn{3}{|l|}{ Age (years) } & 0.019 & & & 0.789 \\
\hline$\leq 25$ & $142(25.18)$ & 104(29.89) & & 278(33.82) & $210(35.12)$ & \\
\hline $26-30$ & 239(42.38) & $161(46.26)$ & & 258(31.39) & 190(31.77) & \\
\hline$\geq 31$ & $183(32.45)$ & $83(23.85)$ & & $286(34.79)$ & 198(33.11) & \\
\hline \multicolumn{3}{|l|}{ Education } & 0.025 & & & $<0.001$ \\
\hline$\leq$ Primary school & 62(10.99) & $20(5.78)$ & & $250(30.53)$ & $98(16.39)$ & \\
\hline Middle school & $272(48.23)$ & $171(49.42)$ & & $460(56.17)$ & $381(63.71)$ & \\
\hline$\geq$ High school & $230(40.78)$ & $155(44.80)$ & & 109(13.31) & $119(19.90)$ & \\
\hline \multicolumn{3}{|l|}{ Employment } & 0.090 & & & 0.885 \\
\hline No & $206(36.52)$ & 108(31.03) & & $126(15.33)$ & $90(15.05)$ & \\
\hline Yes & $358(63.48)$ & $240(68.97)$ & & 696(84.67) & $508(84.95)$ & \\
\hline \multicolumn{3}{|c|}{ Annual personal expenditure (Chinese Yuan) } & 0.314 & & & $<0.001$ \\
\hline Poorest & $60(10.66)$ & $30(8.62)$ & & $270(32.89)$ & 104(17.42) & \\
\hline Poorer & 86(15.28) & $53(15.23)$ & & 192(23.39) & $132(22.11)$ & \\
\hline Middle & $120(21.31)$ & $63(18.10)$ & & 144(17.54) & $142(23.79)$ & \\
\hline Richer & 114(20.25) & $89(25.57)$ & & $140(17.05)$ & 123(20.60) & \\
\hline Richest & 183(32.50) & $113(32.47)$ & & 75(9.14) & $96(16.08)$ & \\
\hline Health score & $86.54 \pm 8.78$ & $88.58 \pm 7.61$ & $<0.001$ & $85.93 \pm 9.20$ & $87.45 \pm 8.39$ & $<0.001$ \\
\hline \multicolumn{3}{|l|}{ Health insurance } & 0.033 & & & 0.280 \\
\hline No & $92(16.31)$ & $39(11.21)$ & & $24(2.92)$ & $12(2.01)$ & \\
\hline Yes & 472(83.69) & 309(88.79) & & 798(97.08) & $586(97.99)$ & \\
\hline \multicolumn{3}{|l|}{ Chronic disease } & 0.024 & & & 0.510 \\
\hline No & 536(95.04) & $341(97.99)$ & & 792(96.35) & 580(96.99) & \\
\hline Yes & $28(4.96)$ & $7(2.01)$ & & $30(3.65)$ & 18(3.01) & \\
\hline \multicolumn{3}{|l|}{ Parity } & 0.064 & & & 0.015 \\
\hline 1 & $368(65.36)$ & 248(71.26) & & $402(49.14)$ & $332(55.70)$ & \\
\hline$\geq 2$ & 195(34.64) & $100(28.74)$ & & $416(50.86)$ & $264(44.30)$ & \\
\hline
\end{tabular}
characteristics ( $n=2332)$ 
definition of CMHS is applied for rural women only (12.13\% vs $\left.19.26 \% ; X^{2}=10.99, P=0.001\right)$, as shown in Fig. 2. For urban women, the rate of CMHS utilisation also increased under the WHO criteria from 15.70 to $20.56 \%$, but this was not a significant change $\left(\chi^{2}=2.57, P=0.109\right)$.

In specific, the GLMM shows that the rates of the utilisation of CMHS after China's 2009 healthcare reform were nearly 5 times (OR $=5.02,95 \% \mathrm{CL}: 1.90$, 13.31) higher for urban women and 15 times $(\mathrm{OR}=$ 14.70, 95\%CL:5.43,39.76) higher for rural women than the rates before healthcare reform (after adjusting for maternal age, education, employment, annual personal expenditure, health score, health insurance, chronic disease and parity, Table 2). Urban and rural women with higher education and health insurance had higher rates of CMHS utilisation after adjusting for other characteristics $(P<0.05$; Table 2$)$. In addition, rural women over 31 years old $(\mathrm{OR}=2.49$,
95\%CL: $1.23,5.06)$ and primigravida $(\mathrm{OR}=0.40$, 95\%CL: $0.21,0.75)$ had higher rates of utilisation.

\section{Improvement in equity of utilisation of CMHS post-reform} Figure 3 shows that before the 2009 reform, concentration curves both in urban and rural women lay significantly below the line of equality, indicating that the utilisation of CMHS was more concentrated among the rich. However, the concentration curves lay above the line of equality after reform. In addition, the CI of occurring CMHS utilisation in urban women decreased significantly $(P=0.021)$ from 0.130 (95\% CL: -0.026 , $0.411)$ to -0.041 (95\% CL: $-0.096,0.007)$. This decreasing trend is also shown for rural women but still favors the rich and is not statistically significant $(P=0.170)$ : specifically, the CI among rural women was $0.104(95 \%$ CL: $-0.012,0.222)$ before reform, and after 0.019 (95\% CL: - 0.014, 0.060, Table 3).
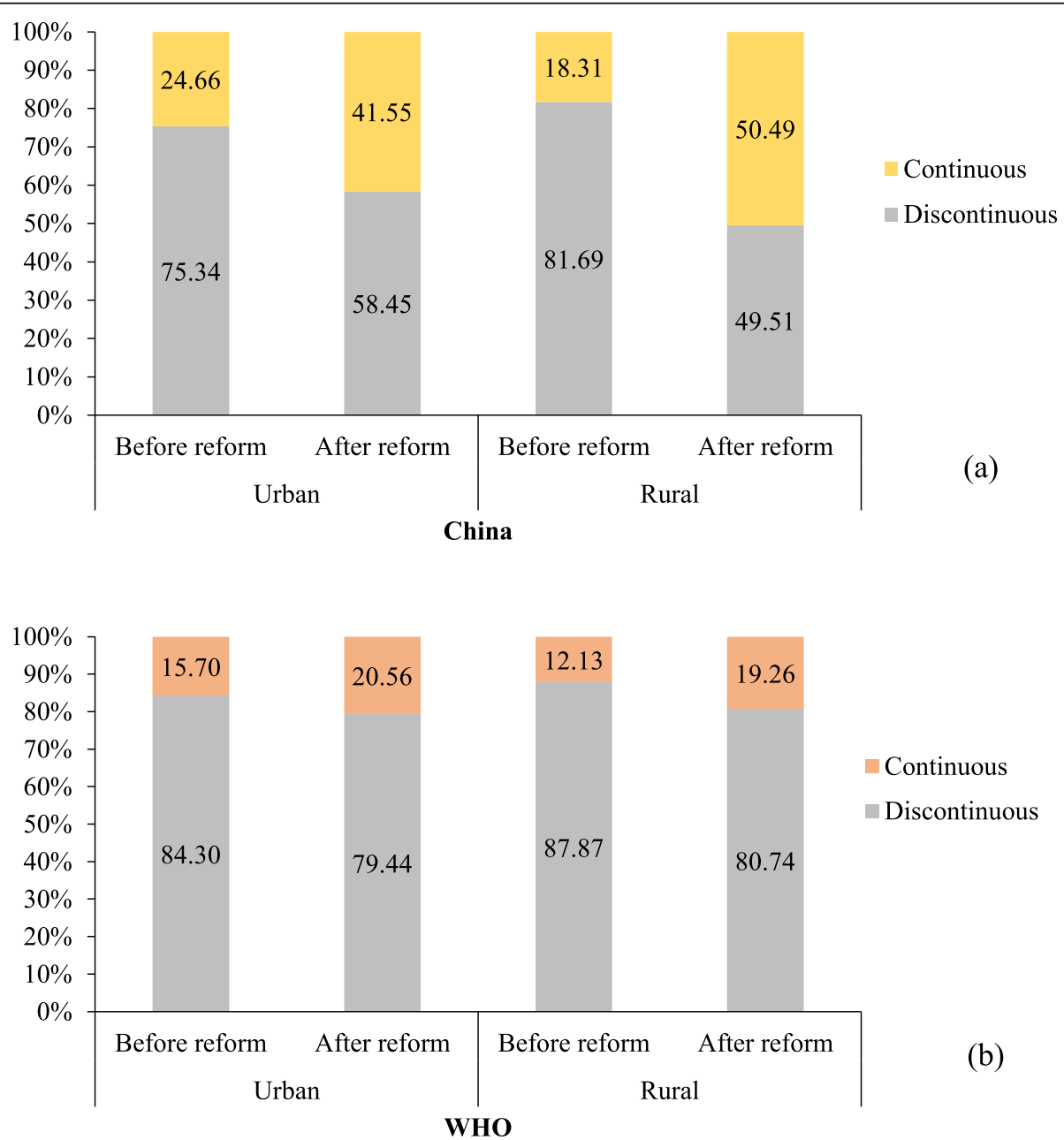

Fig. 2 Comparison of continuous maternal health service utilisation before and after healthcare reform 
Table 2 Determinants of continuum of care for maternal health service utilisation by generalised linear mixed model $(n=2332)$

\begin{tabular}{|c|c|c|c|c|c|c|}
\hline \multirow[t]{2}{*}{ Variables } & \multicolumn{3}{|c|}{ Urban $(n=912)$} & \multicolumn{3}{|c|}{ Rural $(n=1420)$} \\
\hline & $\mathrm{OR}$ & $95 \% C L$ & $P$ & $\mathrm{OR}$ & $95 \% C L$ & $P$ \\
\hline \multicolumn{7}{|l|}{ Healthcare reform } \\
\hline Before & 1.00 & & & 1.00 & & \\
\hline After & 5.02 & $1.90,13.31$ & 0.001 & 14.70 & $5.43,39.76$ & $<0.001$ \\
\hline \multicolumn{7}{|l|}{ Age (years) } \\
\hline$\leq 25$ & 1.00 & & & 1.00 & & \\
\hline $26-30$ & 1.10 & $0.62,1.96$ & 0.741 & 1.40 & $0.80,2.44$ & 0.239 \\
\hline$\geq 31$ & 0.78 & $0.38,1.59$ & 0.493 & 2.49 & $1.23,5.06$ & 0.012 \\
\hline \multicolumn{7}{|l|}{ Education } \\
\hline$\leq$ Primary school & 1.00 & & & 1.00 & & \\
\hline Middle school & 2.62 & $0.98,7.03$ & 0.056 & 3.11 & $1.64,5.92$ & 0.001 \\
\hline$\geq$ High school & 4.18 & $1.30,13.44$ & 0.016 & 4.55 & $1.88,11.01$ & 0.001 \\
\hline \multicolumn{7}{|l|}{ Employment } \\
\hline No & 1.00 & & & 1.00 & & \\
\hline Yes & 1.47 & $0.86,2.49$ & 0.156 & 1.12 & $0.62,2.03$ & 0.697 \\
\hline \multicolumn{7}{|c|}{ Annual personal expenditure (Chinese Yuan) } \\
\hline Poorest & 1.00 & & & 1.00 & & \\
\hline Poorer & 0.94 & $0.35,2.50$ & 0.899 & 1.27 & $0.67,2.41$ & 0.454 \\
\hline Middle & 0.64 & $0.24,1.67$ & 0.357 & 1.70 & $0.85,3.41$ & 0.132 \\
\hline Richer & 0.96 & $0.37,2.47$ & 0.934 & 1.04 & $0.51,2.12$ & 0.910 \\
\hline Richest & 0.51 & $0.19,1.37$ & 0.183 & 1.94 & $0.86,4.39$ & 0.112 \\
\hline Health score & 1.03 & $1.00,1.07$ & 0.051 & 1.02 & $0.99,1.05$ & 0.147 \\
\hline \multicolumn{7}{|l|}{ Health insurance } \\
\hline No & 1.00 & & & 1.00 & & \\
\hline Yes & 2.67 & $1.13,6.30$ & 0.026 & 4.25 & $1.00,18.13$ & 0.05 \\
\hline \multicolumn{7}{|l|}{ Chronic disease } \\
\hline No & 1.00 & & & 1.00 & & \\
\hline Yes & 0.35 & $0.08,1.49$ & 0.156 & 0.75 & $0.23,2.50$ & 0.642 \\
\hline \multicolumn{7}{|l|}{ Parity } \\
\hline 1 & 1.00 & & & 1.00 & & \\
\hline$\geq 2$ & 0.62 & $0.32,1.20$ & 0.155 & 0.40 & $0.21,0.75$ & 0.005 \\
\hline
\end{tabular}

Abbreviations: $O R$ odds ratio, $C L$ confidence limits

The majority of the CMHS inequality was attributable to education, economic statuses and health insurance by defining the contributions as a proportion of each variable; Tables 4 and 5 present the decomposition of CIs of CMHS utilisation, describing the contribution of different population variables to the inequality of CMHS utilisation and the proportion of contribution in the overall CIs. A positive (negative) contribution represented the variable raised (reduced) the pro-rich inequality. For CMHS utilisation among urban women, we found that economic status, health insurance and parity had the largest (112.36\%), second-largest (24.08\%) and thirdlargest (11.99\%) contributions respectively to the inequality of CMHS. For rural women, economic status, education and health insurance had the largest $(52.12 \%)$, second-largest (38.53\%) and third-largest (10.01\%) contributions respectively to the inequality of CMHS utilisation. HI of CMHS utilisation postreform was -0.047 for urban women, evidencing a pro-poor inequity; the horizontal inequity index was 0.019 for rural women and indicating a pro-rich inequity (Tables 4 and 5).

\section{Discussion}

CMHS is one of the ways to improve maternal health and should be effective both in policy and in reality $[37,38]$. This is the first known study to measure the influence of China's 2009 healthcare reform on the utilisation of CMHS in Shaanxi Province. In the 10 years since China's 2009 healthcare reform, many studies focused on different geographies and health conditions have demonstrated its contribution to improving population health status [15, 39-41]. In this study, we found the 2009 healthcare reform has had a positive influence on improving the rate and equity of CMHS utilisation for both urban and rural women. The horizontal inequity index of CMHS utilisation decreased from 0.111 to 0.019 among rural women after the healthcare reform, but remains more concentrated among the richer rural women. Findings from the decomposition of inequality in rural CMHS indicated the horizontal inequity index were mainly explained by educational and economic status (annual personal expenditure), conforming with previous studies analysing health inequity [26, 27]. The educational and economic status were positively associated with CMHS and have positive contribution, highlighting that the richer and more educated rural women were more likely to have CMHS. One potential reason to explain this was that the richer and more educated individuals could be better accessible to healthcare $[18,19]$. Therefore, the contributions of key determinants should be considered by policy-makers when formulating health policy interventions.

According to the concept and principles of maternal health services, to achieve full health for women throughout the pregnancy period, each woman should have $\geq 4$ times antenatal visits, skilled delivery and $\geq 3$ times postnatal visits throughout the maternity period [42], with CMHS putatively improving self-awareness and utilisation rates. However, this study found that the utilisation rates of CMHS have increased after China's 2009 healthcare reform but still remains low. Studies in other LMICs have shown that the rate of CMHS utilisation is low because of shortages in 


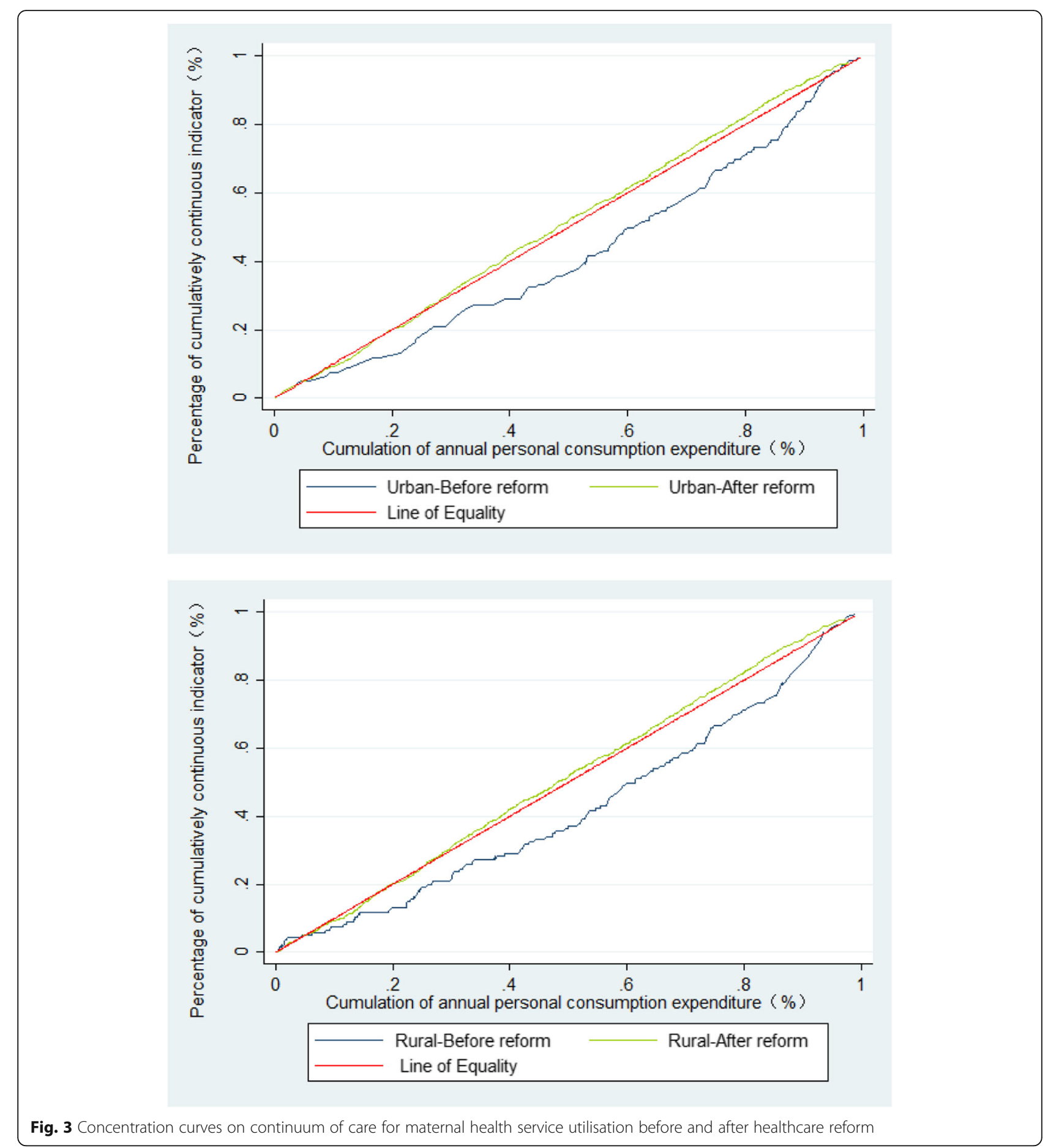

human, financial resources and inadequate healthsystem infrastructure (although they used a different way to assess the continuum of care). Studies showed $6.8 \%$ of maternal women completed the continuum of maternal, newborn and child health services in a rural district of Lao People's Democratic Republic [22]; $5.0 \%$ of maternal women completed at least four antenatal visits, hospital delivery and at least once postnatal visits continuously in Ratanakiri, Cambodia [12]; $41 \%$ of maternal women completed at least one 
Table 3 Inequality of urban and rural women's continuum of care for maternal health service utilisation before and after healthcare reform $(n=2332)$

\begin{tabular}{|c|c|c|c|c|c|c|c|}
\hline \multirow[t]{3}{*}{ Area } & \multicolumn{3}{|c|}{ Before healthcare reform } & \multicolumn{3}{|c|}{ After healthcare reform } & \multirow[t]{3}{*}{$P$} \\
\hline & \multirow[t]{2}{*}{$\mathrm{Cl}$} & \multicolumn{2}{|l|}{$95 \% \mathrm{CL}$} & \multirow[t]{2}{*}{$\mathrm{Cl}$} & \multicolumn{2}{|l|}{$95 \% C L$} & \\
\hline & & Lower & Upper & & Lower & Upper & \\
\hline UrDd & 0.130 & -0.026 & 0.411 & -0.041 & -0.096 & 0.007 & 0.021 \\
\hline ural & 0.104 & -0.012 & 0.222 & 0.019 & -0.014 & 0.060 & 0.17 \\
\hline
\end{tabular}

Abbreviations: $\mathrm{Cl}$ concentration index, $\mathrm{CL}$ confidence limits antenatal visit, hospital delivery and at least one postnatal visit continuously in Nepal [23]; 7.9\% of women completed the continuum of care through continuous visits to health facilities in Ghana [43]. The post-reform survey data in this study showed only $20.56 \%$ of urban women and $19.26 \%$ of rural women made CMHS. Exploring the determinants of the CMHS's utilisation rate, education and health insurance were positively associated with this rate. Considering the poor maternal health outcomes achieved in China, more efforts should be made for policy-makers to increase women's education and coverage health insurance in order to improve the rate of continuum of care for maternal health service.

Table 4 Decomposition analysis of concentration index on urban women's continuum of care for maternal health service utilisation before and after healthcare reform $(n=912)$

\begin{tabular}{|c|c|c|c|c|c|c|c|c|}
\hline \multirow[t]{2}{*}{ Variables } & \multicolumn{4}{|c|}{ Before healthcare reform $(n=222)$} & \multicolumn{4}{|c|}{ After healthcare reform $(n=690)$} \\
\hline & Elasticity & $\mathrm{Cl}$ & Contribution to $\mathrm{Cl}$ & $\%$ & Elasticity & $\mathrm{Cl}$ & Contribution to $\mathrm{Cl}$ & $\%$ \\
\hline \multicolumn{9}{|l|}{ Age (years) } \\
\hline$\leq 25$ & Reference & & & & Reference & & & \\
\hline $26-30$ & -0.286 & 0.062 & -0.018 & -13.70 & 0.080 & 0.033 & 0.002 & -6.42 \\
\hline$\geq 31$ & -0.138 & 0.012 & -0.002 & -1.30 & 0.005 & -0.039 & -0.0002 & 0.50 \\
\hline \multicolumn{9}{|l|}{ Education } \\
\hline$\leq$ Primary school & Reference & & & & Reference & & & \\
\hline Middle school & 1.491 & -0.234 & -0.350 & -268.90 & 0.200 & -0.077 & -0.015 & 37.40 \\
\hline$\geq$ High school & 2.210 & 0.175 & 0.387 & 297.50 & 0.135 & 0.142 & 0.019 & -46.98 \\
\hline \multicolumn{9}{|l|}{ Employment } \\
\hline No & Reference & & & & Reference & & & \\
\hline Yes & -0.029 & -0.444 & 0.001 & 0.99 & 0.153 & -0.009 & -0.001 & 3.37 \\
\hline \multicolumn{9}{|c|}{ Annual personal expenditure (Chinese Yuan) } \\
\hline Poor & Reference & & & & Reference & & & \\
\hline Poorer & 0.055 & -0.069 & -0.004 & -2.96 & -0.056 & -0.770 & 0.043 & -105.54 \\
\hline Middle & -0.004 & 0.280 & -0.001 & -0.96 & -0.104 & -0.357 & 0.037 & -90.68 \\
\hline Richer & 0.072 & 0.449 & 0.033 & 25.01 & -0.107 & -0.066 & -0.007 & 17.16 \\
\hline Richest & 0.040 & 0.545 & 0.022 & 16.95 & -0.253 & 0.480 & -0.121 & 296.16 \\
\hline Health score & 2.961 & 0.005 & 0.014 & 10.47 & 0.621 & 0.003 & 0.002 & -4.74 \\
\hline \multicolumn{9}{|l|}{ Health insurance } \\
\hline No & Reference & & & & Reference & & & \\
\hline Yes & 0.289 & -0.078 & -0.023 & -17.40 & 0.275 & -0.036 & -0.010 & 24.08 \\
\hline \multicolumn{9}{|l|}{ Chronic disease } \\
\hline No & Reference & & & & Reference & & & \\
\hline Yes & -0.012 & 0.029 & -0.0003 & -0.27 & -0.012 & -0.202 & 0.002 & -6.04 \\
\hline \multicolumn{9}{|l|}{ Parity } \\
\hline 1 & Reference & & & & Reference & & & \\
\hline$\geq 2$ & -0.219 & -0.029 & 0.006 & 4.82 & -0.281 & -0.018 & 0.005 & -11.99 \\
\hline Needs variables & - & - & -0.006 & -4.80 & - & - & 0.006 & -16.70 \\
\hline $\mathrm{HI}^{4}$ & - & - & 0.136 & - & - & - & -0.047 & - \\
\hline
\end{tabular}

Abbreviations: $\mathrm{Cl}$ concentration index, \% pure percentage contributions of determinants to the socioeconomic inequality in continuum of maternal health service utilisation, $\mathrm{HI}$ horizontal inequity index. Needs variables mean contribution of factors to $\mathrm{Cl}$, including age, health score and chronic disease 
Table 5 Decomposition analysis of concentration index on rural women's continuum of care for maternal health service utilisation before and after healthcare reform $(n=1420)$

\begin{tabular}{|c|c|c|c|c|c|c|c|c|}
\hline \multirow[t]{2}{*}{ Variables } & \multicolumn{4}{|c|}{ Before healthcare reform $(n=416)$} & \multicolumn{4}{|c|}{ After healthcare reform $(n=1004)$} \\
\hline & Elasticity & $\mathrm{Cl}$ & Contribution to $\mathrm{Cl}$ & $\%$ & Elasticity & $\mathrm{Cl}$ & Contribution to $\mathrm{Cl}$ & $\%$ \\
\hline \multicolumn{9}{|l|}{ Age (years) } \\
\hline$\leq 25$ & Reference & & & & Reference & & & \\
\hline $26-30$ & -0.004 & 0.033 & -0.0001 & -0.14 & 0.031 & -0.014 & -0.0004 & -2.29 \\
\hline$\geq 31$ & 0.284 & -0.023 & -0.007 & -6.38 & 0.058 & -0.022 & -0.001 & -6.69 \\
\hline \multicolumn{9}{|l|}{ Education } \\
\hline$\leq$ Primary school & Reference & & & & Reference & & & \\
\hline Middle school & 0.350 & 0.029 & 0.010 & 9.70 & 0.160 & -0.011 & -0.002 & -8.87 \\
\hline$\geq$ High school & 0.135 & 0.131 & 0.018 & 17.09 & 0.058 & 0.154 & 0.009 & 47.40 \\
\hline \multicolumn{9}{|l|}{ Employment } \\
\hline No & Reference & & & & Reference & & & \\
\hline Yes & -0.104 & 0.0003 & -0.0001 & -0.03 & 0.059 & 0.002 & 0.0001 & 0.64 \\
\hline \multicolumn{9}{|c|}{ Annual personal expenditure (Chinese Yuan) } \\
\hline Poor & Reference & & & & Reference & & & \\
\hline Poorer & 0.048 & 0.288 & 0.014 & 13.29 & 0.005 & -0.413 & -0.002 & -11.71 \\
\hline Middle & 0.032 & 0.661 & 0.021 & 20.16 & 0.025 & -0.008 & -0.002 & -10.57 \\
\hline Richer & 0.006 & 0.875 & 0.006 & 5.316 & -0.005 & 0.329 & -0.002 & -9.12 \\
\hline Richest & 0.034 & 1.072 & 0.036 & 34.82 & 0.019 & 0.755 & 0.015 & 77.19 \\
\hline Health score & -0.005 & -0.001 & 0.000 & 0.004 & 0.620 & 0.002 & 0.001 & 6.33 \\
\hline \multicolumn{9}{|l|}{ Health insurance } \\
\hline No & Reference & & & & Reference & & & \\
\hline Yes & 0.722 & 0.0004 & 0.0003 & 0.29 & 0.303 & -0.006 & -0.002 & -10.01 \\
\hline \multicolumn{9}{|l|}{ Parity } \\
\hline 1 & Reference & & & & Reference & & & \\
\hline$\geq 2$ & -0.918 & -0.005 & 0.004 & 4.22 & -0.315 & -0.003 & 0.001 & 4.38 \\
\hline Needs variables & - & - & -0.007 & -6.52 & - & - & -0.0004 & -2.65 \\
\hline $\mathrm{HI}^{4}$ & - & - & 0.111 & - & - & - & 0.0194 & - \\
\hline
\end{tabular}

Abbreviations: $\mathrm{Cl}$ concentration index; \% Pure percentage contributions of determinants to the socioeconomic inequality in continuum of maternal health service utilisation; $\mathrm{HI}$ Horizontal inequity index. Needs variables mean contribution of factors to $\mathrm{Cl}$, including age and health score

\section{Limitations}

This is the first study, to our knowledge, that studied the influence of China's 2009 healthcare reform on the CMHS utilisation in Shaanxi Province. However, there are some limitations to this study. Firstly, all the data were self-reported and therefore may include recall or social desirability bias. However, the recall bias is likely to be small because pregnancy and childbirth are events that women remember for years [18]. Secondly, the measured determinants of CMHS utilisation available are limited by the pre-specified questions in the survey and there could be some potential unobserved confounding factors for which we did not control. Lastly, the imbalanced sample size before $(n=638)$ and after $(n=1694)$ the reform of interest may have some potential impacts on the results and conclusions, such as potentially introducing more selection bias and resulting with larger standard error and reduced statistical significance.

\section{Conclusions}

This study showed China's 2009 healthcare reform has had positive influence on improving the rate and equity of CMHS utilisation for both urban and rural women in Shaanxi province. Addressing economic and educational gaps between the rich and the poor should be considered by policy-makers when formulating health policy interventions to improve health inequities for rural women. 


\section{Supplementary information}

Supplementary information accompanies this paper at https://doi.org/10. 1186/s12939-020-01179-3.

Additional file 1: Supplementary Questionnaire S1. The household questionnaire of the fourth National Health Service Survey.

Supplementary Questionnaire S2. The household questionnaire of the fifth National Health Service Survey.

\section{Abbreviations}

CMHS: Continuum of care for maternal health services; $\mathrm{Cl}$ : Concentration Index; CL: Confidence Limits; LMICs: Low and Middle Income Countries; MMR: Maternal mortality rate; NHSS: National Health Service Survey; OR: Odds risk; WHO: World Health Organisation

\section{Acknowledgements}

We express our appreciation to all participants in this study for their participation and co-operation, to the leaders and staff of Shaanxi Health Commission, to the guides from the sample counties for their co-operation and organisation in the data collection.

\section{Authors' contributions}

JG was responsible for the field working including data collection and management. ZZ and $\mathrm{HL}$ provided constructive suggestions on data analysis. FX, DW and $C L$ were responsible for the sorting of data. FX and DS did the statistical analysis. The manuscript was prepared by FX, MBK, CL, DW and ZZ. All authors read and approved the final manuscript.

\section{Funding}

This study was funded by the 65th batch of China Postdoctoral Science Foundation Grant (No.2019 M653684).

\section{Availability of data and materials}

This data was drawn from the fourth and fifth National Health Services Survey of Shaanxi Province. They are available from the Shaanxi National Health Commission for researchers who meet the criteria for access to confidential data, and are not opened to everyone. Researchers who want to use these data should contact Zhongliang Zhou (zzliang1981@163.com).

\section{Ethics approval and consent to participate}

In this study, verbal informed consent was obtained by surveyors from each participant before the investigation. Before investigation, the Shaanxi Health Commission delivered a document, and guiders from the sample counties would contact each participant who agreed to accept the interview, and make an appointment with them. The surveyors then went to the participants' house and collected information in questionnaire, which means if we have the participant's questionnaire, we have got the participant' consent. This method of consent was approved by the Ethics Committee of Xi'an Jiaotong University, the approval number were 2014-204 and 2015644 separately. It conformed to the ethics guidelines of the Declaration of Helsinki.

\section{Consent for publication}

Not applicable.

\section{Competing interests}

The authors declare that they have no competing interests.

\section{Author details}

${ }^{1}$ School of Public Policy and Administration, Xi'an Jiaotong University, No. 28 Xianning West Road, Xi'an 710049, Shaanxi, China. ${ }^{2}$ Department of International Public Health, Liverpool School of Tropical Medicine, L3 5QA Liverpool, UK. ${ }^{3}$ MARCH Centre, London School of Hygiene and Tropical Medicine, London WC1E 7HT, UK. ${ }^{4}$ Department of Clinical Sciences, Liverpool School of Tropical Medicine, Liverpool L3 5QA, UK. ${ }^{5}$ School of Public Health and Management, Binzhou Medical University, Shandong, Yantai 264003, China. ${ }^{6}$ Department of Epidemiology and Health Statistics, School of Public Health, Center of Medical Science, Xi'an Jiaotong University Health Science Center, 76 Yanta West Road, Xi'an 710061, China.
Received: 12 December 2019 Accepted: 24 April 2020

Published online: 19 June 2020

\section{References}

1. Alkema L, Chou D, Hogan D, Zhang S, Moller AB, Gemmill A, Fat DM, Boerma T, Temmerman M, Mathers C, Say L. Global, regional, and national levels and trends in maternal mortality between 1990 and 2015, with scenario-based projections to 2030: a systematic analysis by the UN maternal mortality estimation inter-agency group. Lancet. 2016;387:462-74.

2. Maternal and reproductive health. http://gamapserver.who.int/gho/ interactive_charts/mdg5 mm/atlas.html.

3. Feng $X L, X u L, G u o a Y$, Ronsmansc C. Socioeconomic inequalities in hospital births in China between 1988 and 2008. Bull World Health Organ. 2011:89: 432-41.

4. Guo S, Fu X, Scherpbier RW, Wang Y, Zhou H, Wang X, Hipgrave DB. Breastfeeding rates in central and western China in 2010: implications for child and population health. Bull World Health Organ. 2013;91:322-31.

5. Kerber KJ, Graft-Johnson JEd, Bhutta ZA, Okong P, Starrs A, Lawn JE. Continuum of care for maternal, newborn, and child health: from slogan to service delivery. Lancet. 2007:370:1358-69.

6. Tinker A, Hoope-Bender P, Azfar S, Bustreo F, Bell R. A continuum of care to save newborn lives. Lancet. 2005:365:822-5.

7. Chaka EE, Parsaeian M, Majdzadeh R. Factors Associated with the Completion of the Continuum of Care for Maternal, Newborn, and Child Health Services in Ethiopia. Multilevel Model Analysis. Int J Prev Med. 2019: 136.

8. Darmstadt GL, Bhutta ZA, DipMathStat SC, Adam T, Walker N, Bernis L, Lancet-Neonatal-Survival-Steering-Team. Evidence-based, cost-effective interventions: how many newborn babies can we save? Lancet. 2005;365: 977-88.

9. Kikuchi K, Ansah EK, Okawa S, Enuameh Y, Yasuoka J, Nanishi K, Shibanuma A, Gyapong M, Owusu-Agyei S, Oduro AR, et al. Effective linkages of continuum of care for improving neonatal, perinatal, and maternal mortality: a systematic review and meta-analysis. Plos One. 2015;10: e0139288. https://doi.org/10.1371/journal.pone.0139288 eCollection 0132015.

10. Mohan D, LeFevre AE, George A, Mpembeni R, Bazant E, Rusibamayila N, Killewo J, Winch PJ, Baqui AH. Analysis of dropout across the continuum of maternal health care in Tanzania: findings from a cross-sectional household survey. Health Policy Plann. 2017;32:791-9. https://doi.org/10.1093/heapol/ czX1005.

11. Mothupi MA-O, Knight L, Tabana H. Measurement approaches in continuum of care for maternal health: a critical interpretive synthesis of evidence from LMICs and its implications for the South African context. BMC Health Serv Res. 2018;18:539. https://doi.org/10.1186/s12913-12018-13278-12914.

12. Kikuchi KA-O, Yasuoka J, Nanishi K, Ahmed A, Nohara Y, Nishikitani M, Yokota F, Mizutani T, Nakashima N. Postnatal care could be the key to improving the continuum of care in maternal and child health in Ratanakiri, Cambodia. Plos One. 2018;13:e0198829. https://doi.org/10.1371/journal.pone 0198829 eCollection 0192018.

13. Yip W, Fu H, Chen AT, Zhai T, Jian W, Xu R, Pan J, Hu M, Zhou Z, Chen Q, et al. 10 years of health-care reform in China: progress and gaps in universal health coverage. Lancet. 2019:1192-204.

14. Wang L, Wang Z, Ma Q. Fang G, Yang JA-O. The development and reform of public health in China from 1949 to 2019. Glob Health. 2019;15:45. https://doi.org/10.1186/s12992-12019-10486-12996.

15. Meng Q, Mills A, Wang L, Han Q. What can we learn from China's health system reform? BMJ. 2019;365:12349. https://doi.org/10.1136/bmj.12349.

16. Opinions on deepening health system reform. Zhongfa 2009 No. 6. 2009. [http://www.china.org.cn/government/scio-press-conferences/2009-04/09/ content 17575378.htm].

17. Li C, Zeng L, Dibley MJ, Wang D, Pei L, Yan H. Evaluation of socio-economic inequalities in the use of maternal health services in rural western China. Public Health. 2015;129:1251-7

18. Shen Y, Yan H, Reija K, Li Q, Xiao SB, Gao JM, Zhou ZL. Equity in use of maternal health services in Western rural China: a survey from Shaanxi province. BMC Health Serv Res. 2014:14:155.

19. Zhang R, Li S, Li C, Zhao D, Guo L, Qu P, Liu D, Dang S, Yan H. Socioeconomic inequalities and determinants of maternal health services in Shaanxi Province, Western China. PLoS One. 2018;13:e0202129. 
20. Tian M, Feng D, Chen X, Chen Y, Sun X, Xiang Y, Yuan F, Feng Z. China's rural public health system performance: a cross-sectional study. PLoS One. 2013:8:1-10.

21. Fan X, Zhou Z, Dang S, Xu Y, Gao J, Zhou Z, Su M, Wang D, Chen G. Exploring status and determinants of prenatal and postnatal visits in western China: in the background of the new health system reform. BMC Public Health. 2017;18:39.

22. Sakuma SA, Yasuoka J, Phongluxa K, Jimba MA. Determinants of continuum of care for maternal, newborn, and child health services in rural Khammouane, Lao PDR. Plos One. 2019;14:e0215635. https://doi.org/10. 1371/journal.pone.0215635 eCollection 0212019.

23. Chalise BA, Chalise M, Bista B, Pandey AR, Thapa S. Correlates of continuum of maternal health services among Nepalese women: Evidence from Nepal Multiple Indicator Cluster Survey. Plos One. 2019;14:e0215613. https://doi. org/10.1371/journal.pone.0215613 eCollection 0212019

24. Wang W, Hong R. Levels and determinants of continuum of care for maternal and newborn health in Cambodia-evidence from a populationbased survey. BMC Pregnancy Childbirth. 2015;15:62. https://doi.org/10. 1186/s12884-12015-10497-12880.

25. Shaanxi Statistical Yearbook [http://tj].shaanxi.gov.cn/upload/2014/indexch. htm].

26. Zhou Z, Zhu L, Zhou Z, Li Z, Gao J, Chen G. The effects of China's urban basic medical insurance schemes on the equity of health service utilisation: evidence from Shaanxi Province. Int J Equity Health. 2014;13:23.

27. Su M, Zhou Z, Si Y, Wei X, Xu Y, Fan X, Chen G. Comparing the effects of China's three basic health insurance schemes on the equity of healthrelated quality of life: using the method of coarsened exact matching. Health Qual Life Outcomes. 2018;16:41. https://doi.org/10.1186/s1295512018-10868-12950.

28. Gao J, Tang S, Tolhurst R, Rao K. Changing access to health services in urban China: implications for equity. Health Policy Plan. 2001;16:302-12.

29. Pardeshi GS. Age heaping and accuracy of age data collected during a community survey in the Yavatmal district, Maharashtra. India J Community Med. 2010;35:391-5.

30. Villar J, Bergsjo P. WHO antenatal care randomized trial: Manual for the implementation of the new model. Geneva: World Health Organization [WHO], 2002; 2002.

31. Sun Z, Hao Y, Zhang M, Liu W. Investigation and analysis on equity of prenatal health care service utilization. Mater Child Health Care China. 2013; 28:581-3.

32. The New Health Syrem Reform [https://baike.baidu.com/item/\%E6\%96\%B0\% E5\%8C\%BB\%E6\%94\%B9\%E6\%96\%B9\%E6\%A1\%88/6815055].

33. Casey MM, Call KT, Klingner JM. Are rural residents less likely to obtain recommended preventive healthcare services? Am J Prev Med. 2001;21: 182-8.

34. Wagstaff $A$. The bounds of the concentration index when the variable of interest is binary, with an application to immunization inequality. Health Econ. 2005; 14:429-32.

35. Wagstaff A, Doorslaer EV. Measuring and testing for inequity in the delivery of health care. J Hum Resour. 2000;35:716-33.

36. Dennis ML, Benova L, Abuya T, Quartagno M, Bellows B, Campell OMR. Initiation and continuity of maternal healthcare: examining the role of vouchers and user-fee removal on maternal health service use in Kenya. Health Policy Plan. 2019;34:120-31.

37. Kemp L, Harris E, McMahon C, Matthey S, Vimpani G, Anderson T, Schmied $\checkmark$, Aslam $\mathrm{H}$. Benefits of psychosocial intervention and continuity of care by child and family health nurses in the pre- and postnatal period: process evaluation. J Adv Nurs. 2013;69:1850-61.

38. Owili PO, Muga MA, Chou YJ, Hsu YH, Huang N, Chien LY: Associations in the continuum of care for maternal, newborn and child health: a population-based study of 12 sub-Saharan Africa countries. BMC Public Health 2016:2016 May 2017;2016:2414. https://doi.org/10.1186/s12889-12 016-13075-12880.

39. He P, Sun Q, Shi L, Meng Q. Rational use of antibiotics in the context of China's health system reform. BMJ. 2019;365:14016. https://doi.org/10.1136/ bmj.14016.

40. Li L, Fu H. China's health care system reform: Progress and prospects. Int J Health Plann Manag. 2017:32:240-53.

41. Zhang L, Cheng G, Song S, Yuan B, Zhu W, He L, Ma X, Meng Q. Efficiency performance of China's health care delivery system. Int J Health Plann Manag. 2017;32:254-63.
42. Indicator Code Book World Health Statistics - World Health Statistic indicators [http://www.who.int/gho/publications/world health_statistics/ WHS2015_IndicatorCompendium.pdf?ua=1].

43. Shibanuma A, Yeji F, Okawa S, Mahama E, Kikuchi K, Narh C, Enuameh Y, Nanishi K, Owusu-Agyei AO, Gyapong M, et al. The coverage of continuum of care in maternal, newborn and child health: a cross-sectional study of woman-child pairs in Ghana. BMJ Glob Health. 2018;3:e000786. https://doi. org/10.1136/bmjgh-002018-000786

\section{Publisher's Note}

Springer Nature remains neutral with regard to jurisdictional claims in published maps and institutional affiliations.
Ready to submit your research? Choose BMC and benefit from:

- fast, convenient online submission

- thorough peer review by experienced researchers in your field

- rapid publication on acceptance

- support for research data, including large and complex data types

- gold Open Access which fosters wider collaboration and increased citations

- maximum visibility for your research: over $100 \mathrm{M}$ website views per year

At BMC, research is always in progress.

Learn more biomedcentral.com/submissions 